\section{Patient and disease characteristics of adult patients with type 1 diabetes in Germany: an analysis of the DPV and DIVE databases}

\author{
Gesine van Mark, Stefanie Lanzinger, Ralf Barion, Michael Degenhardt, Simone Badis, \\ Horst Noll, Thomas Danne, Peter Bramlage iD, Jochen Seufert and Reinhard W. Holl
}

\begin{abstract}
Background: An understanding of the current status of patients with type 1 diabetes mellitus (T1DM) can help to provide appropriate treatment.

Methods: This was a retrospective analysis of the Dlabetes Versorgungs-Evaluation (DIVE) and the Diabetes-Patienten-Verlaufsdokumentation (DPV) databases for Germany.

Results: The analysis included 56,250 people with T1DM (54.2\% male), a median age of 36.8 years, and a median diabetes duration of 12.4 years. $15.3 \%$ were obese (body mass index $\geq$ $30 \mathrm{~kg} / \mathrm{m}^{2}$ ). Long-acting insulin analogs were used by $53.3 \%$, short-acting analogs by $72.1 \%$, and oral antidiabetic drugs by $4.7 \%$. Patients had a median glycosylated hemoglobin (HbA1c) of $7.8 \%$. There was a drop in $\mathrm{HbA} 1 \mathrm{c}$ and an increase in the rate of hypertension, oral antidiabetic drug use, and in the rate of severe hypoglycemia (all $p<0.01$ ) with age. Flash glucose monitoring (FGM) showed the best glucose values with fewer complications compared to other monitoring systems. HbA1c and FBG were lower in patients using a pump versus multiple daily injections (MDIs; 7.7 versus $7.9 \%$ and 7.8 versus $8.7 \mathrm{mmol} / \mathrm{l}$; all adjusted $p<0.01$ ).

Patients had a lower risk of at least one severe hypoglycemic or DKA episode during the most recent treatment year with pump treatment compared to MDI $19.4 \%$ versus $10.5 \%$ and $4.7 \%$ versus $6.1 \%$, both adjusted $p<0.01$.

Conclusion: The data demonstrated less-than-optimal glycemic control in the young, an increasing metabolic pattern in T1DM with increasing age, a benefit of FGM to improve HbA1c control and adverse effects, as well as benefits of pump treatment over MDIs.
\end{abstract}

Keywords: age, epidemiology, glucose monitoring, type 1 diabetes

Received: 16 October 2018; revised manuscript accepted: 21 January 2019.

\section{Introduction}

The incidence of type 1 diabetes mellitus (T1DM) is increasing worldwide. ${ }^{1,2}$ In Europe, the incidence rate of childhood T1DM is rising by $3-4 \%$ per annum, ${ }^{3,4}$ with 28,200 children newly diagnosed in $2017 . .^{4}$

Individuals with T1DM have an increased risk of cardiovascular (CV) disease and a reduced life expectancy compared with the general population. ${ }^{5-8} \mathrm{~T} 1 \mathrm{DM}$ adversely affects health-related quality of life, daily physical activities and work productivity, and is associated with increased use of medical resources. ${ }^{9}$ Intensive therapy can reduce the risk of microvascular and macrovascular complications associated with T1DM. ${ }^{10,11}$

A clear understanding of the current status and characteristics of individuals with T1DM can help medical practitioners provide appropriate treatment and facilitate the development of strategies to improve the care of patients with T1DM. The aim of the current study was to characterize
Ther Adv Endocrinol Metab

2019, Vol. 10: 1-15

DOI: $10.1177 /$ 2042018819830867

(c) The Author(s), 2019. Article reuse guidelines: sagepub.com/journalspermissions
Correspondence to: Peter Bramlage Institut für Pharmakologie und Präventive Medizin,

Bahnhofstraße 20, 4966 Cloppenburg, Germany peter.bramlagedaippmed.de Gesine van Mark Institut für Pharmakologie und Präventive Medizin,

Cloppenburg, Germany

Stefanie Lanzinger Reinhard W. Holl Institut für Epidemiologie und medizinische Biometrie, ZIBMT, Universität UIm,

Ulm, Germany

Deutsches Zentrum für Diabetesforschung Eingetragener Verein,

München-Neuherberg, Germany

Ralf Barion

Diabetespraxis RheinSieg, Niederkassel-Rheidt, Germany

Michael Degenhardt

Diabetespraxis Dr.

Degenhardt, VillingenSchwenningen, Germany

Simone Badis Hausarztpraxis Badis, Wittlich, Germany

Horst Noll

Klinik für Innere Medizin und interdisziplinäre Intensivmedizin, Sankt Marienkrankenhaus Rodalben, Germany

Thomas Danne

Kinderkrankenhaus auf der Bult, Diabeteszentrum für Kinder und Jugendliche, Hannover. Germany

Jochen Seufert Medizinische Fakultät, Universitätsklinikum

Freiburg, Freiburg, Germany 
patient, disease, and treatment characteristics of a large cohort of adults with T1DM from within the DIabetes Versorgungs-Evaluation (DIVE) and Diabetes-Patienten-Verlaufsdokumentation (DPV) databases (Austria, Germany, Luxemburg, Switzerland) and to explore the balance of benefits (e.g. HbA1c) and risks [hypoglycemia, diabetic ketoacidosis (DKA)] of treatment in this patient population.

\section{Methods}

\section{Study design and data sources}

Data were obtained from the DIVE registry and the DPV database, which were combined for this analysis.

The DIVE registry was established in Germany in 2011.12 Consecutive patients with diabetes mellitus, regardless of their disease stage and treatment strategy, were enrolled at 152 outpatient clinics across the country. Data were entered into the database using DIAMAX (axaris - software \& systeme $\mathrm{GmbH}$ ) or DPV software. The protocol was approved by the ethics committee of the Medical School of Hannover, Germany on 25 August 2011 (no. 6003), and all patients included in the DIVE registry provided written informed consent.

The DPV database was established in $1995 .{ }^{13} \mathrm{~A}$ total of 424 centers in Germany, Austria, Switzerland, and Luxemburg contributed data. Every 6 months, data on patients with diabetes mellitus are prospectively documented using the DPV software and the anonymized data are sent to the University of Ulm, Ulm, Germany. The DPV initiative was approved by the ethics committee of the University of Ulm on 14 August 2009 (no. 202/09), and data collection was approved by local review boards. All patients gave their written consent prior to enrolment in the registry.

For the current analysis, only adult patients from Germany with T1DM, aged 18 years or more, who were registered between 2000 and 2017 , including information on their pharmacotherapy, were included (Figure 1). Patients with 'latent autoimmune diabetes in adults' were excluded.

\section{Documentation}

Data regarding age, sex, body mass index (BMI), blood pressure, diabetes duration, glycosylated hemoglobin (HbAlc), fasting blood glucose (FBG), CV risk factors, current comorbidities, current therapy [insulin, use of pump or multiple daily injections (MDIs; defined as four to eight injections/day), adjuvant oral antidiabetic medication], and glucose monitoring [self-monitoring of blood glucose (SMBG), continuous blood glucose monitoring (CGM) and flash glucose monitoring (FGM)] were collected for the current analysis.

Hypertension definition was based on blood pressure levels $>140 \mathrm{mmHg}$ systolic or $>90 \mathrm{mmHg}$ diastolic or receiving antihypertensive drugs (or any combination of these) which can be considered conservative in patients with diabetes. A sedentary lifestyle was defined as performing physical activity less than once a week. Coronary artery disease was defined as prior myocardial infarction (MI) or angina pectoris. A cardiovascular event was defined as prior MI or stroke. HbAlC values were standardized to the Diabetes Control and Complications Trial (DCCT) reference range (20-42 $\mathrm{mmol} / \mathrm{mol} ; 4.05-6.05 \%)$. Therefore, the multiple of the mean transformation method was used. ${ }^{14}$ In line with previous DIVE/DPV analyses, hypoglycemia with coma was defined as a loss of consciousness or an occurrence of seizures. ${ }^{15}$ For severe hypoglycemia, the definition of the American Diabetes Association Workgroup on Hypoglycemia was used: 'an event requiring assistance by another person to actively administer carbohydrates, glucagon, or other resuscitative actions.' 16

\section{Statistics}

Data from all patients were combined and analyzed as a single data set. For each patient, data of the most recent treatment year in the period 2000-2017 were aggregated (median) before analysis. For current therapy, information prior to the most recent visit was used. Patients documented in both databases (DIVE and DPV) were only included once in the analysis. Descriptive analyses were conducted for the overall study population, as well as stratified by age group (18$25,26-49$ and $>49$ years), ${ }^{17}$ pump versus MDI use, and by glucose-monitoring scheme (SMBG, CGM, FGM). 


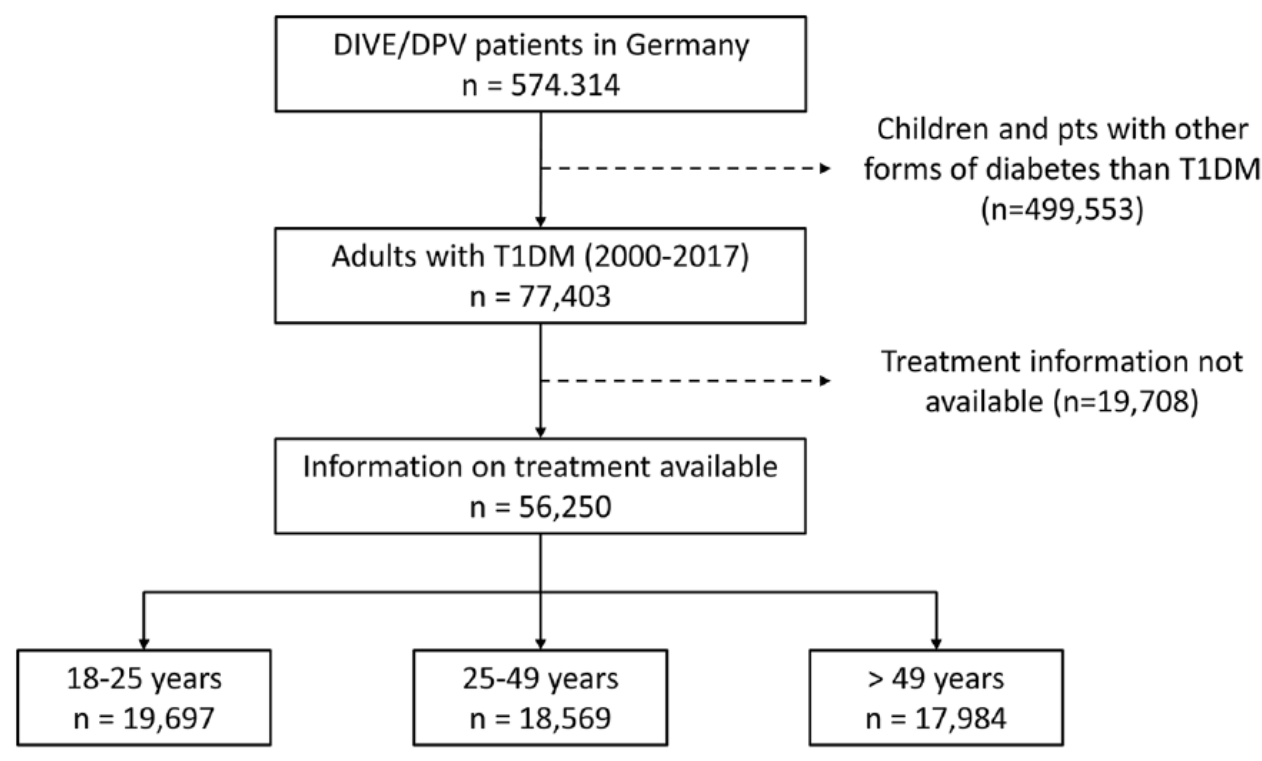

Figure 1. Data included in the present analysis.

DIVE, Dlabetes Versorgungs-Evaluation registry; DPV, Diabetes-Patienten-Verlaufsdokumentation database; T1DM, type 1 diabetes mellitus.

Categorical variables are presented as percentages, and continuous variables are presented as medians with first and third quartiles $(\mathrm{Q} 1, \mathrm{Q} 3)$. $p$ values of unadjusted comparisons were calculated using a chi-squared or Kruskal-Wallis test. HbA1c, FBG, proportion of patients having at least one severe hypoglycemic episode, proportion of patients having at least one diabetic ketoacidotic episode and comorbidities were the outcomes of main interest. Multivariable linear and logistic regression models were conducted to study differences in the main outcomes by age group, pump versus MDIs, as well as by glucose-monitoring scheme. Models were adjusted for sex, age groups, and diabetes duration (categorized as less than 5 years, 5 to less than 10 years, 10 to less than 20 years and 20 years or more). A $p$ value $<$ 0.05 was considered statistically significant. $p$ values from regression models were corrected for multiple comparison using the Tukey-Kramer method in case more than two groups were compared. Statistical analysis was performed using SAS version 9.4. (SAS Institute Inc.)

\section{Results}

The analysis included a total of 56,250 patients with T1DM (Table 1). The median age was 36.8 years, and $54.2 \%$ were male. Participants had had diabetes for a median 12.4 years. Median BMI was $24.6 \mathrm{~kg} / \mathrm{m}^{2}$ and median systolic/diastolic blood pressure was $128.0 / 76.0 \mathrm{mmHg}$. The most common risk factors recorded were a sedentary lifestyle $(55.5 \%)$, followed by hypertension (42.0\%; Figure 2), smoking $(25.5 \%)$ and being overweight $(30.8 \%)$ or obese $(15.3 \%)$. There was a high rate of peripheral artery disease (PAD; 7.3\%), while adverse cardiovascular events such as coronary heart disease (CHD), prior $\mathrm{MI}$ and prior stroke were less frequently reported.

\section{Current therapy and glucose control}

Long-acting insulin analogs were used by $53.3 \%$ of the total cohort and short-acting insulin analogs by $72.1 \%$ (Table 2). Nearly two thirds of participants (63.1\%) were using MDIs and $24.3 \%$ a pump. Overall, $97.0 \% \quad(n=$ $46,569 / 48,605$ where information on SMBG was available) were performing SMBG, a mean of 29.9 times per week, and $1.3 \%(n=138+$ $614 / 56,250)$ were using CGM or FGM. The most common adjuvant noninsulin antidiabetic medication was metformin (3.8\%); other types of oral medications were each used by $<1 \%$ of participants. The resulting median FBG level for the total cohort was $8.4 \mathrm{mmol} / 1$. Median 


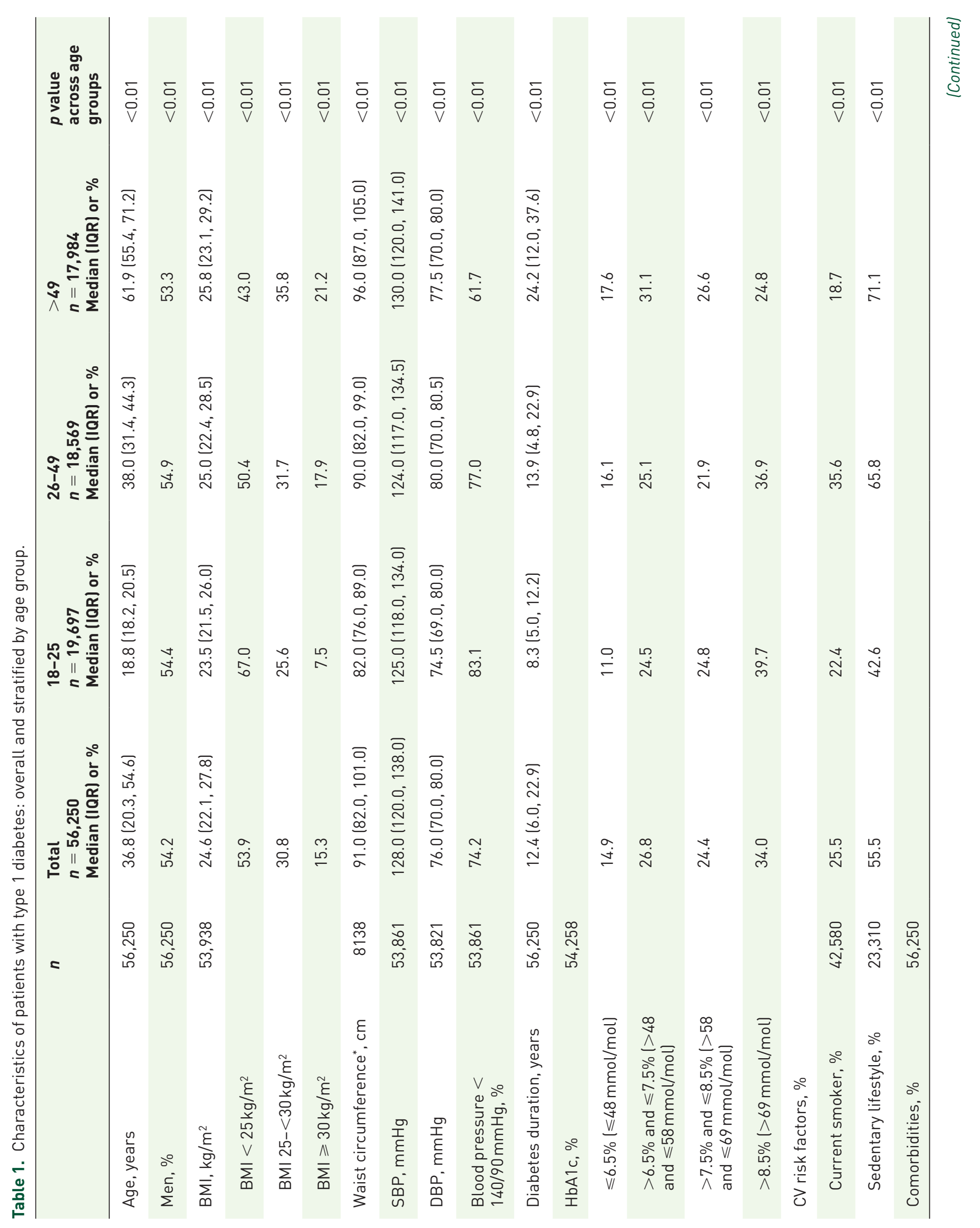




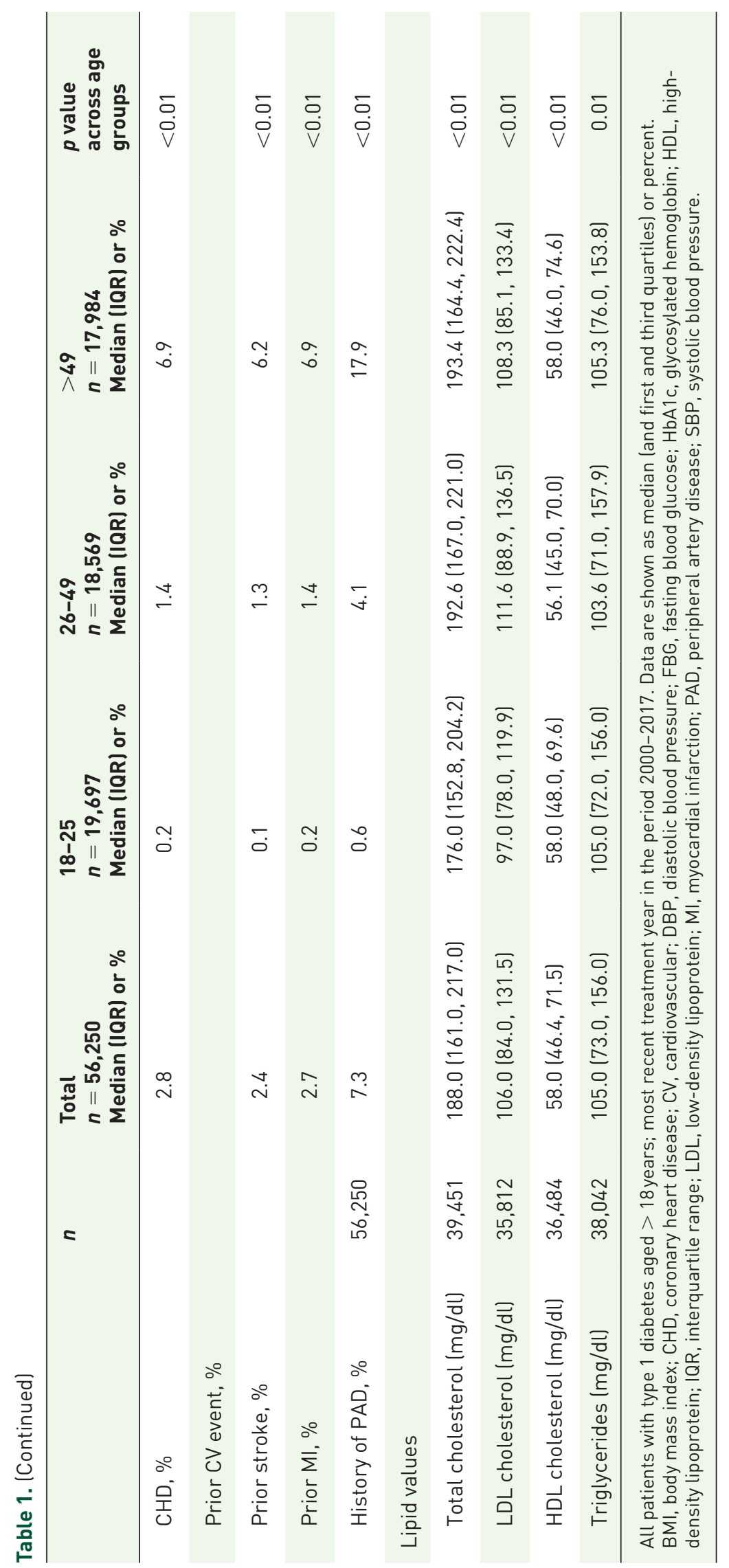



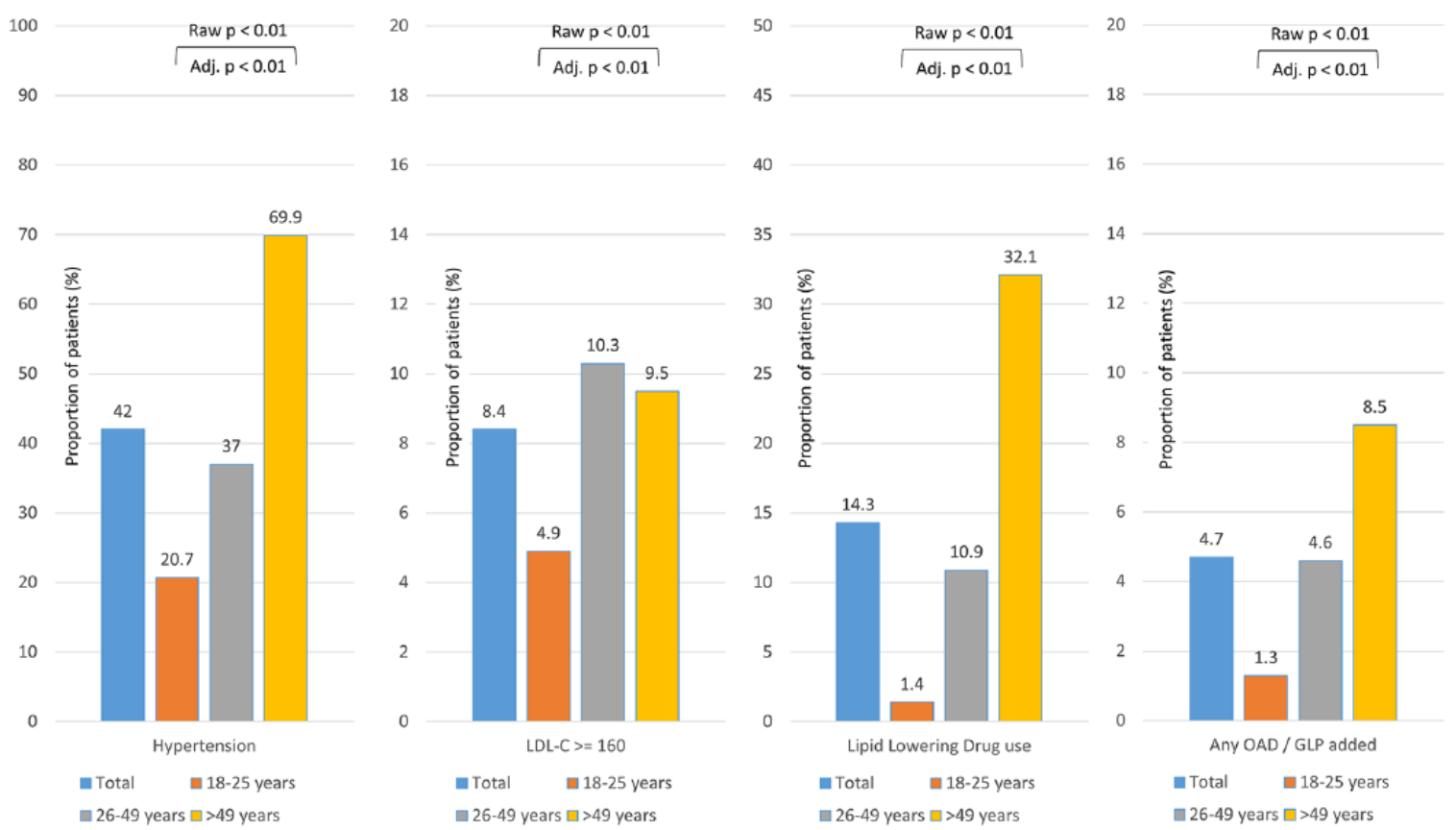

Figure 2. Comorbidity and concomitant drug treatment.

*Adjusted for age, sex and diabetes duration, calculated by logistic regression.

Adj., adjusted; GLP, glucagon-like peptide; OAD, oral antidiabetic; LDL-C, low-density lipoprotein cholesterol; OAD, oral antidiabetic.

HbAlc was $7.8 \%$ (Figure 3), and more than half of participants had an $\mathrm{HbAlc}$ value $>$ $7.5 \%$. Among the entire cohort, $10.4 \%$ of people experienced at least one severe hypoglycemia and $5.8 \%$ experienced at least one DKA episode during the most recent treatment year (Figure 3).

\section{Differences between age groups}

Of the 56,250 patients with T1DM included in this analysis, 19,697 were aged 18-25years, 18,569 were aged $26-49$ years and 17,984 were aged $>49$ years, with significant differences in most baseline characteristics being apparent (Table 1). Median BMI increased progressively with age, from $23.5 \mathrm{~kg} / \mathrm{m}^{2}$ among those aged $18-25$ years to $25.8 \mathrm{~kg} / \mathrm{m}^{2}$ among those aged $>49$ years $(p<0.01)$. Among CV risk factors, the prevalence of obesity increased progressively with age (from $7.5 \%$ at age $18-25$ years to $21.2 \%$ at age $>49$ years), as did the proportion with a sedentary lifestyle (from $42.6 \%$ to $71.1 \%)$. The prevalence of risk factors and comorbidities increased progressively with age: comparing the 18-25-year-old age group with those aged $>49$ years, the rates of hypertension increased from $20.7 \%$ to $69.9 \%$, PAD from $0.6 \%$ to $17.9 \%$, CHD from $0.2 \%$ to $6.9 \%$, prior MI from $0.2 \%$ to $6.9 \%$, and prior stroke from $0.1 \%$ to $6.2 \%$ (all $p<0.01$ ).

Differences in therapy were also evident between age groups (Table 2). A greater percentage of people in the younger age groups were taking short-acting insulin analogs compared with the group aged $>49$ years $(74.9 \%$ versus $73.9 \%$ versus $67.3 \%$; $p<0.01$ ). Pump usage decreased progressively with age (from $30.7 \%$ at $18-25$ years to $16.1 \%$ at $>49$ years; $p$ $<0.01)$, while MDI use varied slightly $(p<$ $0.01)$. Use of all types of adjuvant noninsulin antidiabetic medication increased progressively with increasing age (all $p<0.01$ ); for example, metformin use increased from $1.2 \%$ in the youngest group to $6.7 \%$ in the oldest group (Supplementary Figure 1).

Median $\mathrm{HbA} 1 \mathrm{c}$ was progressively lower in olderage groups $(p<0.01)$, with values decreasing from $8.1 \%$ among $18-25$-year olds to $7.5 \%$ among those aged $>49$ years (Figure 3 ). The 
Table 2. Current therapy for patients with type 1 diabetes: overall and stratified by age group.

\begin{tabular}{|c|c|c|c|c|c|c|}
\hline & $n$ & $\begin{array}{l}\text { Total } \\
n=56,250 \\
\text { Mean (SD) or \% }\end{array}$ & $\begin{array}{l}\text { 18-25 years } \\
n=19,697 \\
\text { Mean (SD) or \% }\end{array}$ & $\begin{array}{l}26-49 \text { years } \\
n=18,569 \\
\text { Mean (SD) or \% }\end{array}$ & $\begin{array}{l}>49 \text { years } \\
n=17,984 \\
\text { Mean (SD) or \% }\end{array}$ & $\begin{array}{l}p \text { value } \\
\text { across age } \\
\text { groups }\end{array}$ \\
\hline \multicolumn{7}{|l|}{ Insulin use } \\
\hline $\begin{array}{l}\text { Insulin short- } \\
\text { acting analogs, \% }\end{array}$ & 56,250 & 72.1 & 74.9 & 73.9 & 67.3 & $<0.01$ \\
\hline $\begin{array}{l}\text { Insulin long- } \\
\text { acting analogs, \% }\end{array}$ & 56,250 & 53.3 & 49.6 & 52.8 & 58 & $<0.01$ \\
\hline \multicolumn{7}{|l|}{ Insulin application } \\
\hline Conv. therapy, \% & 56,250 & 12.6 & 6.4 & 13.0 & 19.0 & $<0.01$ \\
\hline Pump, \% & 56,250 & 24.3 & 30.7 & 25.3 & 16.1 & $<0.01$ \\
\hline MDIs, \% & 56,250 & 63.1 & 62.8 & 61.7 & 64.9 & $<0.01$ \\
\hline \multicolumn{7}{|l|}{$\begin{array}{l}\text { Blood glucose } \\
\text { measurement }\end{array}$} \\
\hline SMBG use, \% & 48,605 & 97.0 & 97.9 & 95.7 & 97.4 & $<0.01$ \\
\hline SMBG \#/week* & 48,605 & $29.9(10.9)$ & $30.1(12.0)$ & 30.7 (10.9) & $28.9(9.5)$ & $<0.01$ \\
\hline CGM/FGM use, \% & 48,586 & 9.6 & 8.7 & 10.0 & 10.4 & $<0.01$ \\
\hline $\begin{array}{l}\text { Adjuvant oral } \\
\text { medication (any) }\end{array}$ & 56,250 & & & & & \\
\hline Metformin & & 3.8 & 1.2 & 3.9 & 6.7 & $<0.01$ \\
\hline Sulfonylurea & & 0.5 & 0.0 & 0.4 & 1.3 & $<0.01$ \\
\hline $\begin{array}{l}\text { Glucosidase } \\
\text { inhibitors }\end{array}$ & & 0.1 & 0.0 & 0.1 & 0.3 & $<0.01$ \\
\hline Glinides & & 0.1 & 0.0 & 0.0 & 0.2 & $<0.01$ \\
\hline DPP-4 inhibitors & & 0.7 & 0.1 & 0.6 & 1.4 & $<0.01$ \\
\hline GLP-1 agonists & & 0.1 & 0.0 & 0.1 & 0.3 & $<0.01$ \\
\hline SGLT-2 inhibitors & & 0.3 & 0.0 & 0.3 & 0.5 & $<0.01$ \\
\hline \multicolumn{7}{|c|}{$\begin{array}{l}\text { All patients with type } 1 \text { diabetes aged >18years, most recent treatment year in the period 2000-2017. } \\
\text { *Mean (SD). } \\
\text { **Oral antidiabetics/GLP. } \\
\text { CGM, continuous glucose monitoring; DPP-4, dipeptidyl peptidase 4; FGM, flash glucose monitoring; GLP-1, glucagon-like peptide } 1 ; \text { MDIs, multiple } \\
\text { daily injections (4-8 injections/day); SD, standard deviation; SGLT-2, sodium-glucose cotransporter-2 (SGLT2); SMBG, self-monitoring of blood } \\
\text { glucose. }\end{array}$} \\
\hline
\end{tabular}

percentage of people with an HbAlc value $>$ $7.5 \%$ also decreased across the age groups $(p<$ 0.01 ). Median FBG did not differ significantly with age. Severe hypoglycemic incidents were progressively more common among older-age groups (Figure 3), increasing from $6.2 \%$ among those aged $18-25$ years to $13.8 \%$ among those aged $>49$ years $(p<0.01)$. The frequency of 

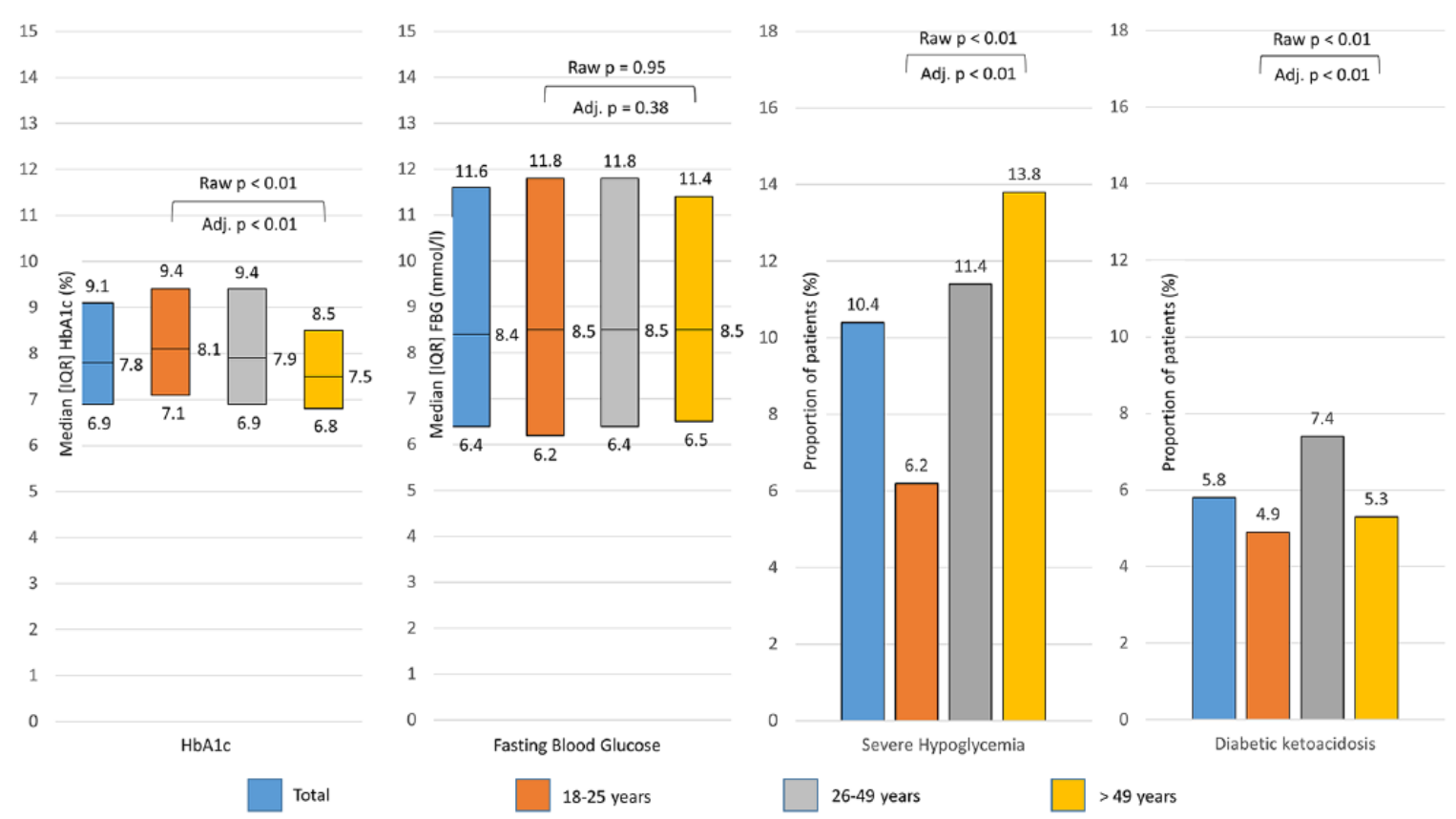

Figure 3. Glucose control and safety overall and by age group.

Median (and first and third quartiles).

*Adjusted for age, sex and diabetes duration, calculated by logistic regression.

Standardized international units for HbA1c: total $62(52-76) \mathrm{mmol} / \mathrm{mol}$; $18-25$ years, 65 (54-79) $\mathrm{mmol} / \mathrm{mol} ; 26-49$ years, 63 (52-79) $\mathrm{mmol} / \mathrm{mol} ;>49$ years, $58(51-69) \mathrm{mmol} / \mathrm{mol}$.

Adj., adjusted; FBG, fasting blood glucose; HbA1c, glycosylated hemoglobin; IQR, interquartile range.

DKA varied from $4.9 \%$ in the youngest age group to $7.4 \%$ at age $26-49$ years to $5.3 \%$ in the oldest group ( $p<0.01$; Figure 3$)$.

\section{Glucose monitoring}

Data on glucose monitoring were available for 46,569 participants using SMBG, 138 using CGM and 614 using FGM (Table 3). The median age of people using FGM (19.3 years) and CGM (20.5 years) was significantly lower than that of SMBG users (36.6 years). There was no difference in the proportion of men/ women using the different types of glucose monitoring. FGM users had a slightly shorter duration of diabetes compared with SMBG users (median 10.0 versus 12.6 years, $p<0.01$ ). Median FBG level was lower among FGM ( $7.9 \mathrm{mmol} / \mathrm{l})$ and CGM (mmol/1) compared with SMBG users $(8.3 \mathrm{mmol} / \mathrm{l})$ with only FGM versus $\mathrm{SMBG}$ reaching statistical significance $(p$ $=0.02)$. Median $\mathrm{HbAlc}$ levels were also reduced with FGM (7.5\%) and CGM (7.5\%) versus SMBG $(7.8 \% ; p<0.01)$. Significantly fewer FGM users (5.7\%) than SMBG users
(11.3\%) experienced severe hypoglycemia, and significantly fewer FGM users $(2.6 \%)$ experienced DKA episode compared with SMBG users $(5.7 \%$; Figure 4$)$.

\section{Pump versus MDI populations}

Characteristics of patients using a pump $(n=$ $13,652)$ or MDIs $(n=35,510)$ are summarized in Table 4. A larger proportion of the MDI group were men compared with pump users $(57.6 \%$ versus $44.2 \%, p<0.01)$. The MDI group was older than the pump group (median 37.4 versus 29.0 years, $p<0.01$ ), but MDI users had diabetes for a shorter time than pump users (median 11.1 versus 14.8 years, $p<0.01$ ). MDI users were more likely to be smokers and have a sedentary lifestyle than pump users $(p<0.01)$. Median FBG was higher in the MDI group than the pump group ( 8.7 versus $7.8 \mathrm{mmol} / 1, p<0.01$ ) (Figure 5). Median HbAlc was $7.9 \%$ in the MDI group and $7.7 \%$ in the pump group $(p<$ $0.01)$ and more participants had an HbAlc value $>7.5 \%(p<0.01)$ in the MDI group than the pump group. 


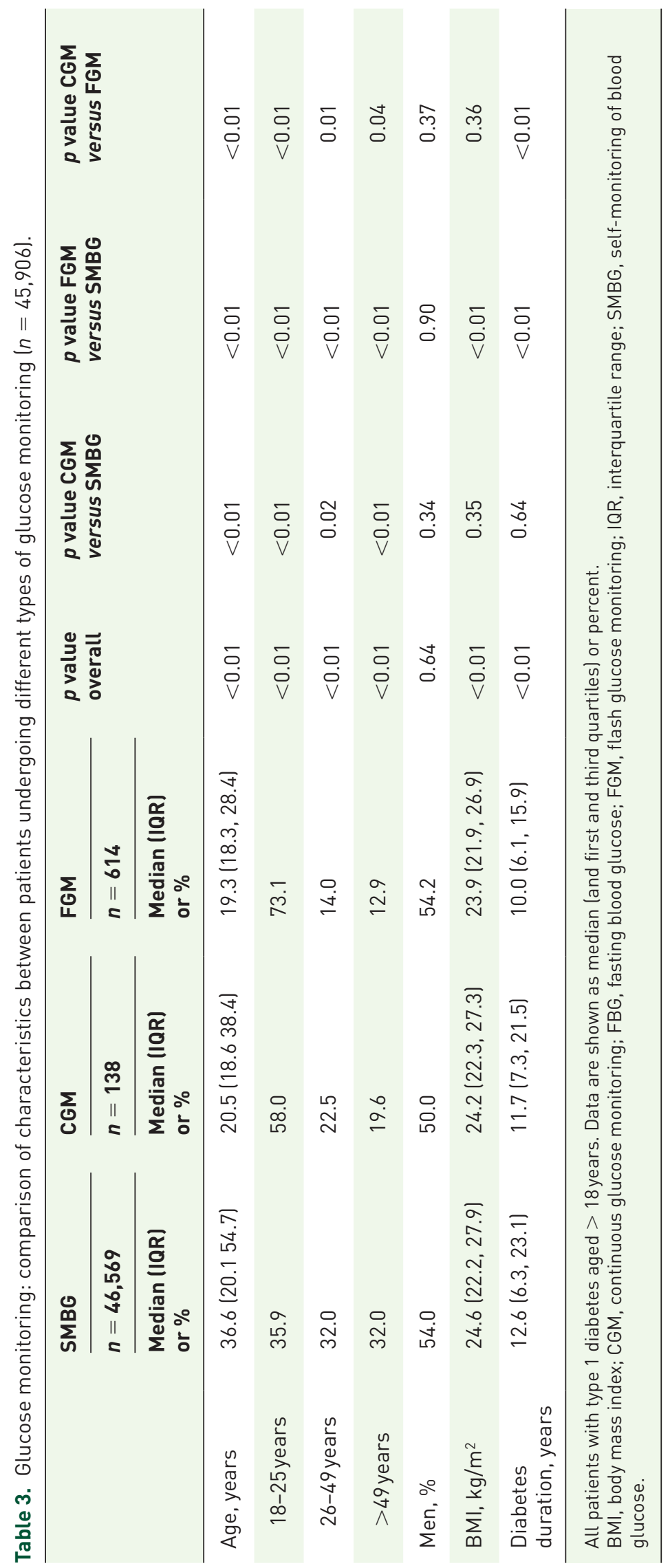




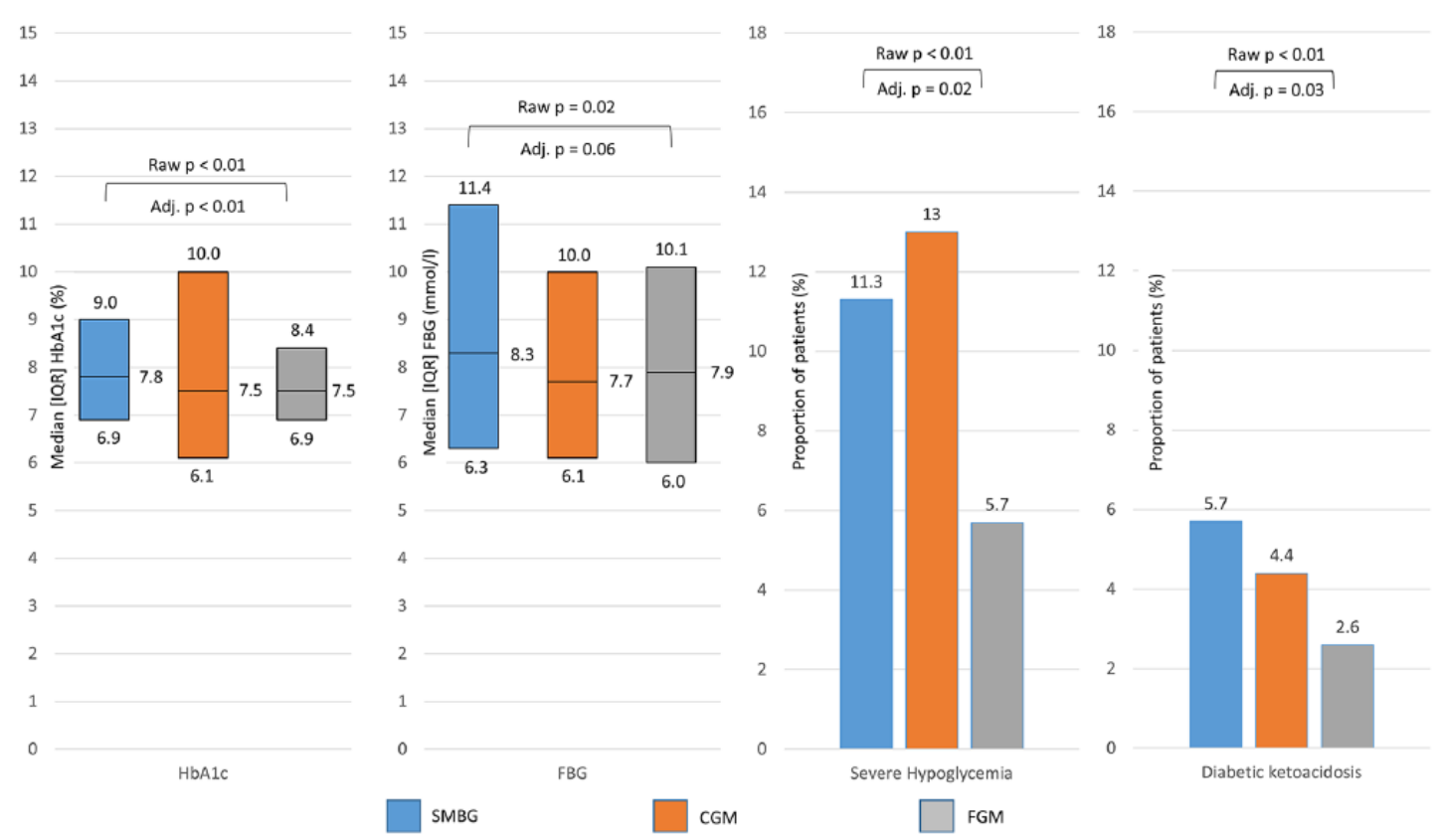

Figure 4. Glucose control and safety by monitoring method.

Median (and first and third quartiles).

*Adjusted for age, sex and diabetes duration, calculated by logistic regression.

Standardized international units for HbA1c: SMBG 62 (52-75) $\mathrm{mmol} / \mathrm{mol}$, CGM 58 (43-86) mmol/mol, FGM 58 (52-68) $\mathrm{mmol} / \mathrm{mol}$.

Adj., adjusted; CGM, continuous glucose monitoring; FBG, fasting blood glucose; FGM, flash glucose monitoring; HbA1c, glycosylated hemoglobin; IQR, interquartile range; SMBG, self-monitoring of blood glucose.
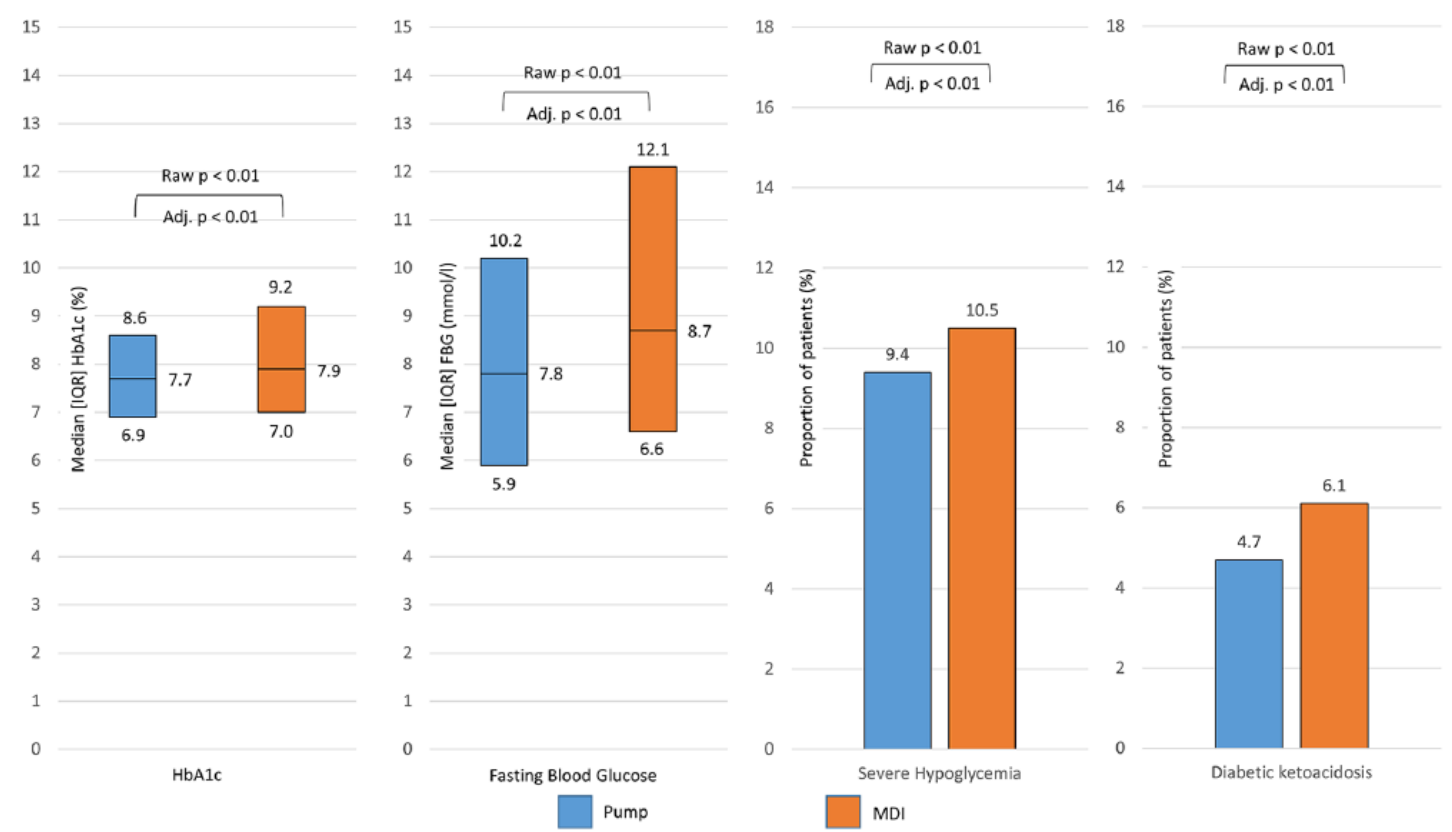

Figure 5. Glycemic control and patients with at least one severe hypoglycemia and at least one diabetic ketoacidosis episode by insulin therapy.

Median (and first and third quartiles).

*Adjusted for age, sex and diabetes duration, calculated by logistic regression.

Standardized international units for HbA1c: SMBG 61 (52-70) $\mathrm{mmol} / \mathrm{mol}$, CGM 63 (53-77) $\mathrm{mmol} / \mathrm{mol}$.

Adj., adjusted; CGM, continuous glucose monitoring; FBG, fasting blood glucose; HbA1c, glycosylated hemoglobin; IQR, interquartile range; MDI, multiple daily injection; SMBG, self-monitoring of blood glucose. 
Table 4. Characteristics of patients with type 1 diabetes stratified by pump and MDI use.

\begin{tabular}{|c|c|c|c|c|c|}
\hline & \multicolumn{2}{|c|}{ Pump (n = 13,652) } & \multicolumn{2}{|c|}{ MDI $(n=35,510)$} & \multirow{2}{*}{$\begin{array}{l}\text { Pump versus } \\
\text { MDI } \\
p \text { value }\end{array}$} \\
\hline & $\begin{array}{l}n \\
\text { available }\end{array}$ & Median (IQR) or \% & $n$ available & Median (IQR) or \% & \\
\hline Age, years & 12,185 & $29.0(19.1,47.3)$ & 35,362 & $37.4(20.3,55.2)$ & $<0.01$ \\
\hline Men, \% & 12,185 & 44.2 & 35,362 & 57.6 & $<0.01$ \\
\hline BMI, kg/m² & 11,639 & $24.9(22.5,28.1)$ & 33,964 & $24.5(22.0,27.8)$ & $<0.01$ \\
\hline $\mathrm{BMI}<25 \mathrm{~kg} / \mathrm{m}^{2}$ & & 51.0 & & 54.8 & $<0.01$ \\
\hline BMI $25-<30 \mathrm{~kg} / \mathrm{m}^{2}$ & & 33.1 & & 30.3 & $<0.01$ \\
\hline $\mathrm{BMI} \geqslant 30 \mathrm{~kg} / \mathrm{m}^{2}$ & & 15.9 & & 14.9 & $<0.01$ \\
\hline Waist circumference, cm & 1622 & $91.5(82.0,101.0)$ & 4902 & $92.0(83.0,102.0)$ & 0.27 \\
\hline $\mathrm{SBP}, \mathrm{mmHg}$ & 11,582 & $125.0(119.5,135.0)$ & 34,003 & $128(120.0,138.0)$ & $<0.01$ \\
\hline $\mathrm{DBP}, \mathrm{mmHg}$ & 12,185 & $75.0(70.0,80.0)$ & 35,362 & $76.0(70.0,80.0)$ & $<0.01$ \\
\hline $\begin{array}{l}\text { Blood pressure } \\
<140 / 90 \mathrm{mmHg}, \%\end{array}$ & 11,582 & 79.6 & 34,003 & 73.3 & $<0.01$ \\
\hline Diabetes duration, years & 12,185 & $14.8(9.0,25.2)$ & 35,362 & $11.1(5.0,21.2)$ & $<0.01$ \\
\hline $\mathrm{HbA} 1 \mathrm{c}, \%$ & 11,712 & & 11,712 & & \\
\hline$\leqslant 6.5 \%(\leqslant 48 \mathrm{mmol} / \mathrm{mol})$ & & 13.3 & & 14.5 & 0.02 \\
\hline $\begin{array}{l}\quad>6.5 \% \text { and } \leqslant 7.5 \%(>48 \\
\text { and } \leqslant 58 \mathrm{mmol} / \mathrm{mol})\end{array}$ & & 31.0 & & 25.7 & $<0.01$ \\
\hline $\begin{array}{l}>7.5 \% \text { and } \leqslant 8.5 \% \text { (>58 } \\
\text { and } \leqslant 69 \mathrm{mmol} / \mathrm{mol})\end{array}$ & & 28.1 & & 23.6 & $<0.01$ \\
\hline$>8.5 \%(>69 \mathrm{mmol} / \mathrm{mol})$ & & 27.5 & & 36.2 & $<0.01$ \\
\hline \multicolumn{6}{|l|}{ CV risk factors, $\%$} \\
\hline Current smoker, \% & 9251 & 21.2 & 27,023 & 27.0 & $<0.01$ \\
\hline Sedentary lifestyle, \% & 5415 & 45.4 & 14,652 & 57.5 & $<0.01$ \\
\hline \multicolumn{6}{|l|}{ Comorbidities, \% } \\
\hline CHD, \% & 12,185 & 1.8 & 35,362 & 2.8 & $<0.01$ \\
\hline Hypertension, \% & 11,649 & 37.0 & 34,205 & 42.3 & $<0.01$ \\
\hline \multicolumn{6}{|l|}{ Prior CV event, \% } \\
\hline Prior stroke, \% & 12,185 & 1.5 & 35,362 & 2.6 & $<0.01$ \\
\hline Prior MI, \% & 12,185 & 1.8 & 35,362 & 2.8 & $<0.01$ \\
\hline History of PAD, \% & 12,185 & 4.5 & 35,362 & 7.1 & $<0.01$ \\
\hline
\end{tabular}

All patients with type 1 diabetes aged > 18years with either pump or MDI, most recent treatment year in the period 2000-2017. Data are shown as median (and first and third quartiles) or percent.

BMI, body mass index; CHD, coronary heart disease; CV, cardiovascular; DBP, diastolic blood pressure; FBG, fasting blood glucose; HbA1c, glycosylated hemoglobin; IQR, interquartile range; MDI, multiple daily injection; MI, myocardial infarction; PAD, peripheral artery disease; SBP, systolic blood pressure. 


\section{Discussion}

This study evaluated the characteristics of a large cohort of 56,250 adults with T1DM and included a comparison of different age groups and a comparison of pump and MDI users. It further explored the balance of benefits (e.g. HbAlc) and risks (hypoglycemia, DKA) of treatment in this patient population. The analyses demonstrated less-than-optimal glycemic control in the young, an increasing metabolic pattern in T1DM with age, a benefit of FGM to improve the balance of $\mathrm{HbA1c}$ control and adverse effects such as hypoglycemia and DKA, as well as the benefits of pump treatment over multidose injections.

\section{General characteristics}

More than half of the study population were men, which is consistent with previous reports on T1DM. $9,18,19$ Only $15.3 \%$ of participants were obese; median BMI was $24.6 \mathrm{~kg} / \mathrm{m}^{2}$, which is similar to values reported previously in Europe and the USA. ${ }^{9,17,19}$ Approximately one quarter of participants were current smokers, and more than half led a sedentary lifestyle, findings which are consistent with other data. ${ }^{9}$ It has been shown previously that physical activity has beneficial effects with respect to glycemic control and comorbidities in people with T1DM, suggesting that increased efforts to promote physical activity in people with T1DM may be worthwhile. ${ }^{20}$

Increasing age and hyperglycemia (higher $\mathrm{HbAlc}$ ) have been shown to be the most important risk factors for CV disease in people with T1DM, although other factors such as blood pressure and lipid levels are also relevant. ${ }^{21}$ In the current study, more than half of people with T1DM had poor glycemic control, as indicated by an $\mathrm{HbAlc}$ value $>7.5 \%$, which is slightly lower than the rate reported for the large T1D Exchange clinic registry in the USA (68\%). ${ }^{17}$ More than $40 \%$ of participants had hypertension, which is higher than the rates reported in small studies in Germany $(18.5 \%)$ and Europe $(28.1 \%),{ }^{9,19}$ even though a conservative definition of hypertension was used and estimates would have been higher considering stringent control targets.

\section{Differences between age groups}

The current analysis found several differences in patient and disease characteristics between different adult age groups. As might be expected, ${ }^{21}$ the prevalence of $\mathrm{CV}$ comorbidities (hypertension, $\mathrm{PAD}, \mathrm{CHD}$, and a history of $\mathrm{MI}$ or stroke) increased with age. CV risk factors, including the rate of obesity, a sedentary lifestyle, and smoking also increased with age, although smoking decreased again in the group aged $>49$ years.

Glycemic control, reflected by HbAlc, was better among older-age groups: almost two thirds of the group aged $18-25$ years had an $\mathrm{HbA} 1 \mathrm{c}$ value $>7.5 \%$ compared with less than half of those aged $>49$ years. Other studies of adults with T1DM have found that glycemic control tends to improve with increasing age. ${ }^{17,22-24}$ Episodes of severe hypoglycemia were more common among older people in the current study, a finding that has been reported previously. ${ }^{17,22} \mathrm{DKA}$ was less common with increasing age, which has also been reported previously. ${ }^{17,25}$

Insulin therapy was less common in the older-age groups, while the use of adjuvant oral antidiabetic medication increased. The proportion of people using MDIs to administer insulin did not differ substantially between the age groups, whereas older participants (aged $>49$ years) were less likely than younger people to be using an insulin pump. The current analysis found that only $16.1 \%$ of those aged $>49$ years used a pump compared with $25.3-30.7 \%$ of younger people. A previous DPV analysis found that only $1.2 \%$ of patients aged $>60$ years used a pump compared with $23.8 \%$ of younger people. ${ }^{22}$ This contrasts with the TIDM population in the USA, where pump use did not differ substantially between adult age groups (age 18-25 years, 55\%; age 2649 years, $63 \%$; age $\geqslant 50$ years, $60 \%$ ). ${ }^{17}$ The reasons for lower pump use among older people in the current study were not identified. The use of metformin and other noninsulin medications increased among older-age groups, which is consistent with data from the USA. ${ }^{17}$

With respect to glucose monitoring, use of CGM/FGM was highest $(10.4 \%)$ in the group aged $>49$ years, although the differences between age groups were modest. In the USA, CGM use was higher in the groups aged 2649 years $(23 \%)$ and $\geqslant 50$ years $(18 \%)$ than among those aged $18-25$ years $(7 \%) .{ }^{17}$ Reasons for the increased use of CGM among older patients were not identified, but it is possible it relates to the increased risk of hypoglycemic episodes in this age group. 


\section{Glucose monitoring}

Frequent SMBG can help improve glycemic control among people with T1DM. ${ }^{26-29}$ In the current analysis, participants performed testing an average 30 times per week (4.3 times per day), which is slight less but essentially consistent with a previous analysis of the DPV database (5.0 times per day $)^{29}$ or for the T1D Exchange registry in the USA (4.7 times per day). ${ }^{17}$

CGM/FGM can help reduce $\mathrm{HbA} 1 \mathrm{c}$ and blood glucose levels. ${ }^{30-33}$ Only $9.6 \%$ of people in the current study were using CGM/FGM. This compares with $11 \%$ among participants in the US T1D Exchange registry. ${ }^{17}$ The reasons for using CGM/FGM were not identified in the current analysis, but the German Diabetes Association recommends that CGM is indicated for patients with frequent severe hypoglycemic episodes, unsatisfactory metabolic control, or who need more than 10 blood glucose measurements per day to achieve $\mathrm{HbA} 1 \mathrm{c}$ target. ${ }^{31}$ A previous analysis of the DPV database found that CGM use by adults with T1DM was associated with significantly lower $\mathrm{HbA} 1 \mathrm{c}$ values, but not with a reduction in hypoglycemic events. ${ }^{30,34}$

\section{Therapy}

The use of insulin pumps may have beneficial effects on outcomes compared with the use of MDIs, probably by reducing the risk of hypoglycemic and hyperglycemic episodes. ${ }^{35} \mathrm{~A}$ previous analysis of the DPV database found that use of insulin pumps among adults with T1DM increased from $13.5 \%$ in 2002 to $31.5 \%$ in 2014.15 This remained rather stable since, with about one quarter of adults with T1DM (24.1\%) using an insulin pump in the current analysis. This is substantially less than the $60 \%$ rate reported in the USA (in an analysis which included all ages from 2 years onwards). ${ }^{17}$

The current study included a comparison of patient characteristics prior to initiating pump or MDI therapy, which found that people starting pump therapy were younger, but had had diabetes for longer, than MDI users. Pump users were less likely than MDI users to be smokers or to have a sedentary lifestyle and had fewer comorbidities. Prior to initiating therapy, people who subsequently started insulin pump therapy had a lower median FBG level, lower median $\mathrm{HbAlc}$, and were less likely to have poor glycemic control
(HbAlc $>7.5 \%)$ than those who started MDI therapy. Overall, this indicates that pumps were more likely to be used by younger, healthier people.

The most common noninsulin medication administered to T1DM patients in the current study was metformin, which is consistent with data from the USA. ${ }^{17}$

\section{Strengths and Limitations}

Participants were recruited at specialized diabetes-care centers interested in participating in diabetes registries. The cross-sectional nature of the study means that causal links between findings cannot be made. The main strengths of the study are the large number of subjects and the fact they came from a routine clinical practice setting and the study thus provides a picture of current realworld practice.

\section{Conclusion}

These data demonstrated less-than-optimal HbAlc-based glycemic control in the young, an increasing metabolic pattern in T1DM with increasing age, a benefit of FGM to improve the balance of HbAlc control and adverse effects such as hypoglycemia and DKA as well as the benefits of pump treatment over multi dose injections.

\section{Acknowledgements}

We thank all participating centers of the DPV and DIVE initiatives, especially those who collaborated in this investigation. JS and RWH shared senior authorship of this paper. CW, RW, SS, AZ, HMR, and TD contributed to the data collection. GvM and PB designed the analysis, drafted the manuscript, and created figures. SL and RWH did the statistical analyses. SL, CW, RW, SS, AZ, HMR, TD, JS and RWH contributed to the discussion and reviewed/edited the manuscript. SL had full access to all the data in the study and takes responsibility for the integrity of the data and the accuracy of the data analysis. All authors approved the final manuscript for submission.

\section{Funding}

The DPV registry was supported by the European Foundation for the Study of Diabetes. Further financial support was provided by the German 
Diabetes Society and the German Center for Diabetes Research. The DIVE registry received funding from Sanofi, AstraZeneca, Bayer, and Abbott and was conducted under the auspices of diabetesDE. Sponsors were not involved in study design, the collection, analysis and interpretation of data, the writing of the report or the decision to submit the article for publication.

\section{Conflict of interest statement}

TD and JS report grants and personal fees and RWH reports grants from Abbott, AstraZeneca, and Sanofi, outside the submitted work. PB reports to have received consultancy honoraria from Sanofi and Abbott. GvM, SL, CW, RW, SS, AZ and HMR have no competing interests to disclose.

\section{Supplemental material}

Supplemental material for this article is available online.

\section{ORCID iD}

Peter Bramlage (iD https://orcid.org/0000-0003 $-4970-2110$

\section{References}

1. Tamayo T, Rosenbauer J, Wild SH, et al. Diabetes in Europe: an update. Diabetes Res Clin Pract 2014; 103: 206-217.

2. Rogers MAM, Kim C, Banerjee T, et al. Fluctuations in the incidence of type 1 diabetes in the United States from 2001 to 2015: a longitudinal study. BMC Med 2017; 15: 199.

3. Patterson CC, Gyurus E, Rosenbauer J, et al. Trends in childhood type 1 diabetes incidence in Europe during 1989-2008: evidence of non-uniformity over time in rates of increase. Diabetologia 2012; 55: 2142-2147.

4. Biester T, Kordonouri O, and Danne T. Pharmacotherapy of type 1 diabetes in children and adolescents: more than insulin? Ther $A d v$ Endocrinol Metab 2018; 9: 157-166.

5. De Ferranti SD, De Boer IH, Fonseca V, et al. Type 1 diabetes mellitus and cardiovascular disease: a scientific statement from the American Heart Association and American Diabetes Association. Diabetes Care 2014; 37: 2843-2863.

6. Livingstone SJ, Levin D, Looker HC, et al. Estimated life expectancy in a Scottish cohort with type 1 diabetes, 2008-2010. IAMA 2015; 313: 37-44.
7. Huo L, Harding JL, Peeters A, et al. Life expectancy of type 1 diabetic patients during 1997-2010: a national Australian registry-based cohort study. Diabetologia 2016; 59: 1177-1185.

8. Rawshani A, Sattar N, Franzen S, et al. Excess mortality and cardiovascular disease in young adults with type 1 diabetes in relation to age at onset: a nationwide, register-based cohort study. Lancet 2018; 392: 477-486.

9. Ryden A, Sorstadius E, Bergenheim K, et al. The humanistic burden of type 1 diabetes mellitus in Europe: examining health outcomes and the role of complications. PLoS One 2016; 11: e0164977.

10. Nathan DM, Genuth S, Lachin J, et al. The effect of intensive treatment of diabetes on the development and progression of long-term complications in insulin-dependent diabetes mellitus. N Engl F Med 1993; 329: 977-986.

11. Nathan DM, Cleary PA, Backlund JY, et al. Intensive diabetes treatment and cardiovascular disease in patients with type 1 diabetes. $N$ Engl $\mathcal{F}$ Med 2005; 353: 2643-2653.

12. Danne T, Kaltheuner M, Koch A, et al. "Diabetes Versorgungs-Evaluation" (DIVE)-a national quality assurance initiative at physicians providing care for patients with diabetes. Dtsch Med Wochenschr 2013; 138: 934-939.

13. Grabert M, Schweiggert F, and Holl RW. A framework for diabetes documentation and quality management in Germany: 10 years of experience with DPV. Comput Methods Programs Biomed 2002; 69: 115-121.

14. Rosenbauer J, Dost A, Karges B, et al. Improved metabolic control in children and adolescents with type 1 diabetes: a trend analysis using prospective multicenter data from Germany and Austria. Diabetes Care 2012; 35: 80-86.

15. Bohn B, Kerner W, Seufert J, et al. Trend of antihyperglycaemic therapy and glycaemic control in 184,864 adults with type 1 or 2 diabetes between 2002 and 2014: analysis of real-life data from the DPV registry from Germany and Austria. Diabetes Res Clin Pract 2016; 115: 31-38.

16. Workgroup on Hypoglycemia, American Diabetes Association. Defining and reporting hypoglycemia in diabetes: a report from the American Diabetes Association Workgroup on Hypoglycemia. Diabetes Care 2005; 28: 1245-1249.

17. Miller KM, Foster NC, Beck RW, et al. Current state of type 1 diabetes treatment in the U.S.: updated data from the T1D Exchange clinic registry. Diabetes Care 2015; 38: 971-978. 
18. Kyvik KO, Nystrom L, Gorus F, et al. The epidemiology of type 1 diabetes mellitus is not the same in young adults as in children. Diabetologia 2004; 47: 377-384.

19. Szendroedi J, Saxena A, Weber KS, et al. Cohort profile: the German Diabetes Study (GDS). Cardiovasc Diabetol 2016; 15: 59.

20. Bohn B, Herbst A, Pfeifer M, et al. Impact of physical activity on glycemic control and prevalence of cardiovascular risk factors in adults with type 1 diabetes: a cross-sectional multicenter study of 18,028 patients. Diabetes Care 2015; 38: 1536-1543.

21. Narres M, Claessen H, Droste S, et al. The incidence of end-stage renal disease in the diabetic (compared to the non-diabetic) population: a systematic review. PLoS One 2016; 11: e0147329.

22. Schutt M, Fach EM, Seufert J, et al. Multiple Complications and frequent severe hypoglycaemia in 'elderly' and 'old' patients with type 1 diabetes. Diabet Med 2012; 29: e176-e179.

23. Mcknight JA, Wild SH, Lamb MJ, et al. Glycaemic control of type 1 diabetes in clinical practice early in the 21 st century: an international comparison. Diabet Med 2015; 32: 1036-1050.

24. Mcbrien KA, Manns BJ, Hemmelgarn BR, et al. The association between sociodemographic and clinical characteristics and poor glycaemic control: a longitudinal cohort study. Diabet Med 2016; 33: 1499-1507.

25. Fazeli Farsani S, Brodovicz K, Soleymanlou $\mathrm{N}$, et al. Incidence and prevalence of diabetic ketoacidosis (DKA) among adults with type 1 diabetes mellitus (T1D): a systematic literature review. BMF Open 2017; 7: e016587.

26. Karter AJ, Ackerson LM, Darbinian JA, et al. Selfmonitoring of blood glucose levels and glycemic control: the Northern California Kaiser Permanente Diabetes registry. Am F Med 2001; 111: 1-9.

27. Schutt M, Kern W, Krause U, et al. Is the frequency of self-monitoring of blood glucose related to long-term metabolic control? Multicenter analysis including 24,500 patients from 191 centers in Germany and Austria. Exp Clin Endocrinol Diabetes 2006; 114: 384-388.

28. Miller KM, Beck RW, Bergenstal RM, et al. Evidence of a strong association between frequency of self-monitoring of blood glucose and hemoglobin A1c levels in T1D Exchange clinic registry participants. Diabetes Care 2013; 36: 2009-2014.

29. Schwandt A, Best F, Biester T, et al. Both the frequency of $\mathrm{HbAlc}$ testing and the frequency of self-monitoring of blood glucose predict metabolic control: a multicenter analysis of 15 199 adult type 1 diabetes patients from Germany and Austria. Diabetes Metab Res Rev 2017; 33 (7). doi: 10.1002/dmrr.2908.

30. Ludwig-Seibold CU, Holder M, Rami B, et al. Continuous glucose monitoring in children, adolescents, and adults with type 1 diabetes mellitus: analysis from the prospective DPV diabetes documentation and quality management system from Germany and Austria. Pediatr Diabetes 2012; 13: 12-14.

31. Liebl A, Henrichs HR, Heinemann L, et al. Continuous glucose monitoring: evidence and consensus statement for clinical use. $\mathcal{F}$ Diabetes Sci Technol 2013; 7: 500-519.

32. Rodbard D. Continuous glucose monitoring: a review of recent studies demonstrating improved glycemic outcomes. Diabetes Technol Ther 2017; 19: S25-S37.

33. Leelarathna L and Wilmot EG. Flash forward: a review of flash glucose monitoring. Diabet Med 2018; 35: 472-482.

34. Desalvo DJ, Miller KM, Hermann JM, et al. Continuous glucose monitoring and glycemic control among youth with type 1 diabetes: international comparison from the T1D exchange and DPV initiative. Pediatr Diabetes 2018; 19: 1271-1275.

35. Steineck I, Cederholm J, Eliasson B, et al. Insulin pump therapy, multiple daily injections, and cardiovascular mortality in 18,168 people with type 1 diabetes: observational study. BMF 2015; 350: h3234.
Visit SAGE journals online journals.sagepub.com/ home/tae

@SAGE journals 